\title{
The effect of several sugars on the growth of Gladosporium herbarum and Trichothecium roseum
}

\author{
Kaija K. Kauppi and Liisa Kaarina Simola \\ Department of Botany, University of Helsinki, Finland
}

\begin{abstract}
Summary. The growth response of two fungi, Cladosporium herbarum (Link.) Fr. and Trichothecium roseum (Bull.) Link., was studied on six carbon sources at three concentrations. Sucrose proved to be the best carbohydrate source for Cladosporium, but Trichothecium could not use this compound for growth. Glucose, mannose and fructose were utilized almost equally well by $C$. herbarum. Glucose was the best carbohydrate for $T$. roseum, and mannose and fructose were also growth-promoting. Galactose and arabinose proved to be very weak carbon sources for both fungi. It seems evident that the carbohydrate composition of the nutrient medium must have a great effect on the growth of these fungi.
\end{abstract}

\section{Introduction}

It has been suggested that mechanisms of susceptibility or resistance to a parasite may involve the sugar content of the host plant (Pohjakallio 1932, Hare 1966). Free sugars are readily available to parasitic fungi. However, the sugar content of plants is usually rather low except in e.g. sugar-cane and sugar-beet. A feature common to several plants studied is that their free sugar pools contain mainly sucrose, glucose and fructose. The relative amounts of these vary greatly with the species and plant organ and the latter's stage of development. For example, the main sugar in pea seeds and leaves is sucrose (Turner et al. 1957) and in apples it is fructose (Evans 1928). Arabinose is a common constituent of the sugar pool in Lathyrus maritimus (Simola 1969).

In the literature there are numerous data concerning the effects of carbohydrates on the growth of a large number of fungi. Examples of the effects of certain sugars on the growth of fungi of different groups are presented in Table 1. These sugars (and their isomers) were reinvestigated in the present study. The nitrogen sources were also inclu- ded, because they are known to influence the utilization of carbon sources by fungi (UNESTAM 1965). Because the growth conditions in different studies have not been uniform, the results are only fully comparable within one study. The following generalizations about utilization of the common monosaccharides and sucrose may be drawn from the data in Table 1:

Sucrose is generally a relatively good source of carbon, especially for the higher fungi (cf. Table 1). However, it is utilized by fewer fungi than D-glucose. For the great majority of fungi D-mannose and D-fructose are equivalent to glucose for growth. Occasionally, one of these may be superior to glucose. In the utilization of L-arabinose and especially of D-galactose there is variation between different fungi.

Cladosporium herbarum (Link.) Fr. is a very common fungus the world over, and occurs as a weak plant parasite on a variety of species, e.g. wheat, pea, blackberry and apples (Butler et al. 1949, Moore 1959). In Finland some species (still undetermined) of the genus Cladosporium are very common on cereals at harvesting (YLIMÄKI 1970).

Trichothecium roseum (Bull.) Link. is 
also a weak parasite on several plants. e.g. cucumber, melon, tomato and apple (MOORE 1959), but is not so common as Cladosporium herbarum. Some species of the genus Trichothecium are also met with on cereals at harvesting in Finland (YLIMÄKI 1970).

The purpose of this study was to examine the growth of Cladosporium herbarum and Trichothecium roseum on different sugars and compare the results with those of previous nutritional studies.

\section{Material and methods}

The strain of Trichothecium roseum for these studies was obtained from the Department of Plant Pathology, University of Helsinki. Cladosporium herbarum was isolated from an infected homoarginine solution.

Stock cultures of these fungi were maintained on Sabouraud agar tubes. The spore suspension was made by transferring spores and hyphae with a platinum loop (diameter $0.4 \mathrm{~cm}$ ) from a stock culture five times to $10 \mathrm{ml}$ of sterile water. The suspension was mixed thoroughly and $1 \mathrm{ml}$ of it was added to each 50-ml Erlenmeyer flask with $25 \mathrm{ml}$ of test medium.

In order to discover a good mineral nutrient medium and suitable vitamins for Trichothecium and Cladosporium, different nutrient media were tested, with 1 per cent glucose as carbon source. Waris's nutrient solution (1962), which contains both nitrate and ammonium nitrogen (together $181 \mathrm{mg} \mathrm{N} / \mathrm{l}$ ), proved to be poorer than Heller's (GAUTHERET 1959) five times concentrated medium, especially at $\mathrm{pH} 6$ (the $\mathrm{pH}$ of Waris's medium at the end of experiment was 3.0-3.1). At pH 6.6 the growth response of Trichothecium in Waris's medium was much better (final $\mathrm{pH} 7.7-8.0$ ). In preliminary experiments the following vitamins (and their concentrations) were not growth-promoting for Cladosporium: thiamine $(100 \mu \mathrm{g} / \mathrm{l})$, biotin (5 $\mu \mathrm{g} / \mathrm{l})$, pantothenic acid $(100 \mu \mathrm{g} / \mathrm{l})$, choline chloride $(100 \mu \mathrm{g} / \mathrm{l})$ and vitamin $\mathrm{B}_{12}(100 \mu \mathrm{g} / \mathrm{l})$. The growth of Trichothecium on addition of thiamine and biotin (studied together) increased by about 25 per cent.

In the light of these preliminary studies we chose Heller's nutrient solution in five times the final concentration, to which biotin $(5 \mu \mathrm{g} / \mathrm{l})$ and thiamine $(100 \mu \mathrm{g} / 1)$ were added. At this concentration Heller's solution contains $500 \mathrm{mg}$ of nitrate nitrogen per 1 . Before the solution was autoclaved, the $\mathrm{pH}$ was adjusted to 6.0 with $0.1 \mathrm{~N}$ $\mathrm{NaOH}$ or HCI. However, the growth of these fungi was the same, whether the initial $\mathrm{pH}$ value of the culture medium was 6.0 or 5.0 .

The following sugars were tested:
$\mathrm{D}+$ glucose
(The British Drug Houses Ltd.)
D-mannose
Levulose
(E. Merck AG)
(Difco)
D (+) galactose (E. Merck AG)
$\mathrm{L}(+)$ arabinose (E. Merck AG)
Sucrose
(The British Drug Houses Ltd.)

Each sugar was tested at three concentrations: 0.25, 1.0 and 2.0 per cent. Portions of $12.5 \mathrm{ml}$ of Heller's mineral solution in tenfold the normal concentration were autoclaved separately from $12.5 \mathrm{ml}$ of the sugar solution in twice the final concentration. The autoclaved solutions were combined in a UV-sterilized cabinet. In each treatment 1 per cent glucose was used as control. At least four replicates were set up. The cultures were incubated at $25^{\circ} \mathrm{C}$ in the dark for 13 days.

Growth was analyzed on the basis of dry weight per culture. After 13 days the cultures were filtered through filter-paper discs of known weights in a Büchner funnel. They were washed thoroughly with distilled water, dried overnight at $105^{\circ} \mathrm{C}$, and weighed.

\section{Results and discussion}

The results of this study are presented in Fig. 1. A review of these shows that there are some clear differences between Cladosporium herbarum and Trichothecium roseum in their ability to utilize various sugars. The dry weights of Trichothecium were always much smaller than the values obtained from Cladosporium.

The most marked difference found between Trichothecium and Cladosporium was in their ability to utilize sucrose. For Cladosporium this was the best sugar of all. Growth was in linear relation to concentration. For Trichothecium it was a poorly utilizable sugar, although this fungus could use both glucose and fructose, the hydrolytic products of sucrose (cf. Fig. 1). The reason is probably the absence of an enzyme which hydrolyses sucrose to glucose and fructose, or of permease enzymes if sucrose is hydrolysed by Trichothecium after permeation (cf. Cirillo 1961). However, a strain isolated by DomsaH (1960) has a high sucrose tolerance.

Monosaccharides are generally favourable sources of carbon for the growth of fungi. The utilization of monosaccharides is assumed to be direct, and the efficiency with 
Table 1. Growth response of fungi belonging to different groups on D-glucose, D-mannose, D-fructose, D-galactose, L-arabinose and sucrose. The results are quoted from the literature.

D- D- D- D- L- N glucose mannose fructose galactose arabinose Sucrose source

Oomycetes:

1. Aphanomyces astaci (Unestam 1965)

2. Araispora sp. (Gleason 1968)

3. Leptomitus lacteus (Gleason 1968)

4. Mindeniella spironosa (Gleason 1968)

5. Phytophtora erythrosep tica (Margolin 1942x)

$+++\begin{array}{lllll}0 & 0 & 0 & \mathrm{NH}_{4} \mathrm{Cl}\end{array}$

$\begin{array}{ccccc}0 & 0 & & 0 & \text { L-asp- } \mathrm{NH}_{2} \\ 0 & 0 & 0 & 0 & \gg\end{array}$

$+++\quad 0 \quad+++\quad 0 \quad+++$ 》

$++\quad++\quad+\quad+\quad++\quad \mathrm{NH}_{4} \mathrm{NO}_{3}$

Zygomycetes:

6. Phycomyces blakesleaanus (Margolin 1942x)

7. Rhizopus oligosporus (Sorenson \& Hesseltine 1966)

$$
\begin{array}{ccccc}
++++++++++++ & ++ & ++ & \mathrm{NH}_{4} \mathrm{NO}_{3} \\
+++ & ++++++++ & \pm & 0 & \mathrm{NH}_{4} \mathrm{Cl}
\end{array}
$$

Ascomycetes:

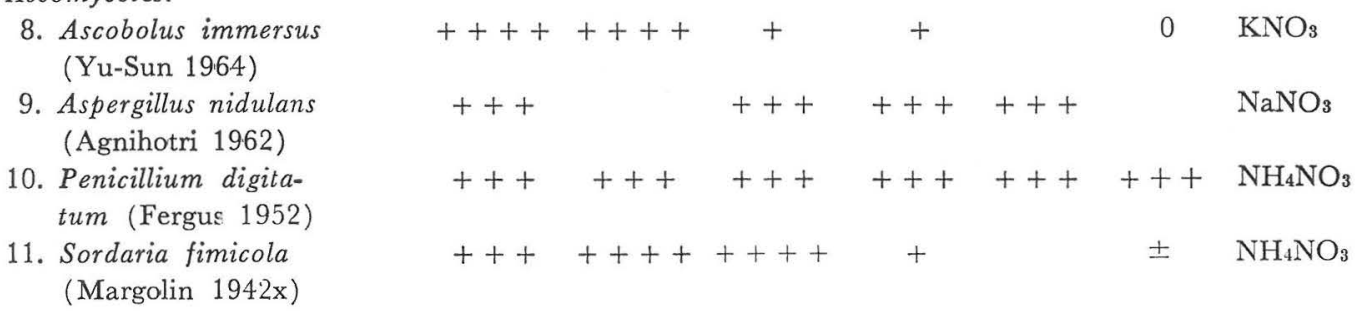

Basidiomycetes:

12. Amanita rubescens (Palmer \& Hacskaylo 1970)

13. Coprinus comatus (Fries 1955)

14. Russula emetica (Palmer \& Hacskaylo 1970)

$\begin{array}{ccccccc}++++ & +++ & ++++ & + & 0 & 0 & \mathrm{NH}_{4} \mathrm{Cl} \\ +++ & ++ & +++ & \pm & & \pm & \left(\mathrm{NH}_{4}\right)_{2} \mathrm{HPO}_{4} \\ +++ & +++ & +++ & \pm & \pm & \pm & \mathrm{NH}_{4} \mathrm{Cl}\end{array}$

Fungi Imperfecti:

15. Fusarium lycopersici (Margolin 1942x)

16. Fusarium roseum (Lopez \& Fergus 1965)

17. Helminthosporium sativum (Margolin 1942x)

$$
\begin{array}{cccccc}
++++ & +++ & +++ & ++++ & ++ & \mathrm{NH}_{4} \mathrm{NO}_{3} \\
++ & & +++ & ++ & ++++ & \mathrm{L}-\text { asp-NH} \\
++ & ++ & +++ & + & +++\mathrm{NH}_{4} \mathrm{NO}
\end{array}
$$

$0=$ no growth

$\pm-++++=$ increasing growth promotion

x) See Lilly \& Barnett 1951, p. 122. 
Fig. 1. The dry weights (mg) of Trichothecium roseum (- - $(-)$ and Cladosporium herbarum $(-)$ grown in different sugars at three concentrations.
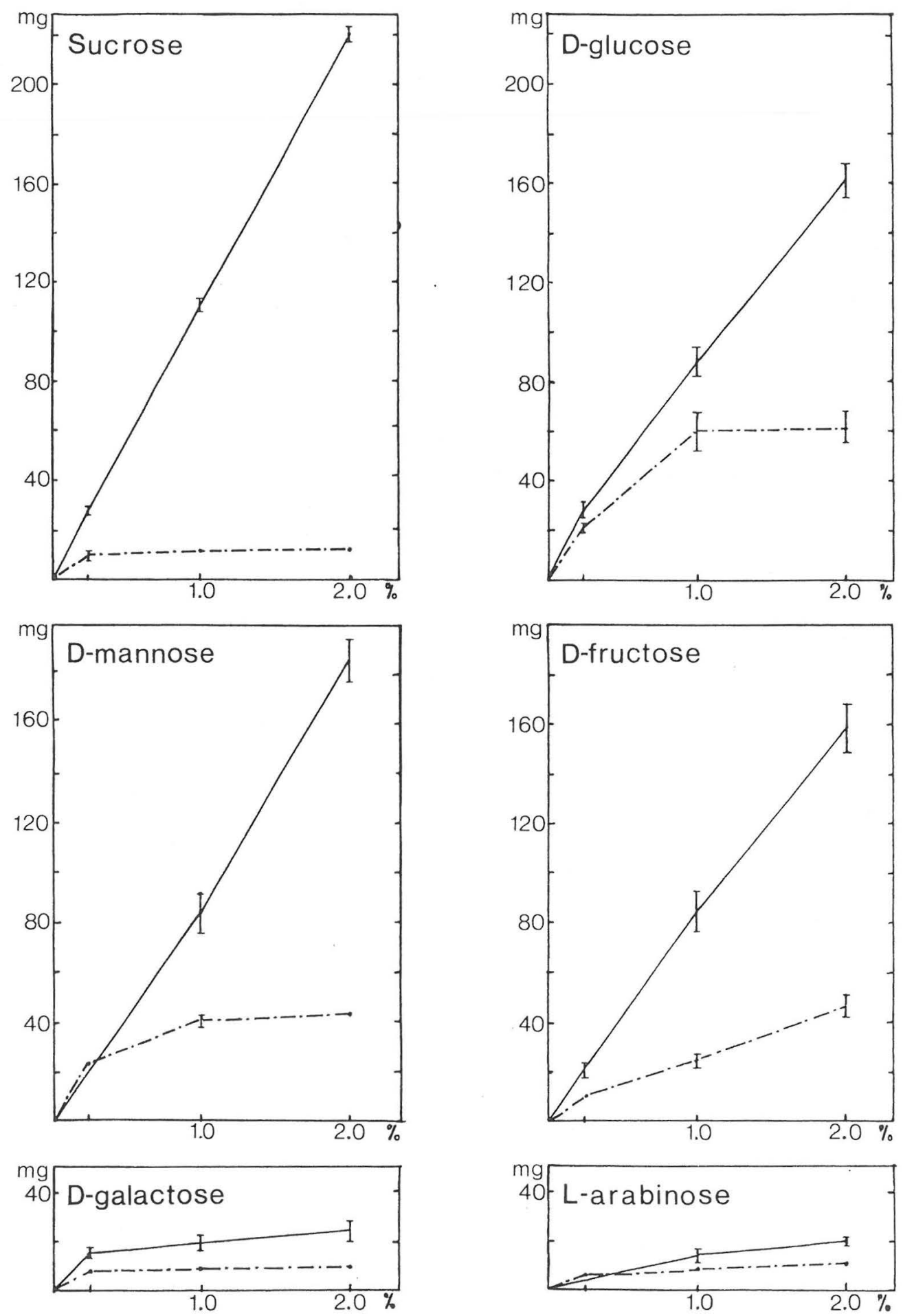
which they are assimilated obviously depends on their chemical structure and on the nature of the organisms. Structural differences between sugars have been used to explain the variations of the utilizability for the growth of fungi (STEINBERg 1942).

Among the hexoses, D-glucose is biologically the most important and is utilized by nearly all fungi (cf. Table 1). The same has been found to be true in the present study. It was the best sugar for $T$. roseum. However, the growth of this fungus was not increased if the concentration of glucose was raised from 1.0 per cent to 2.0 per cent. The growth of Cladosporium, on the other hand, was in linear relation to concentration.

D-Glucose, D-mannose and D-fructose are structurally similar from carbon 3 to carbon 6 , and for the great majority of fungi (e.g. Phycomyces blakesleaanus, Penicillium digitatum, Table 1) D-fructose and D-mannose are equivalent to $\mathrm{D}$-glucose. The same was found to be true of Cladosporium. However, at a concentration of 2.0 per cent mannose was markedly superior to glucose. In Trichothecium we find that the closer the structural resemblance of a sugar to glucose, the better it serves as a carbon source. Particularly among the lower fungi there appear to be exceptions to the general rule that fructose and mannose are equivalent to glucose (cf. Table 1).

D-Galactose was a poor carbon source for both Trichothecium and Cladosporium. Galactose has been reported to be unavailable to many fungi and if it is used as the sole source the rate of initial growth is often slow (FRIES 1955).

The inability to use galactose is well known from the cultivation of several different organisms, such as bacteria, algae, yeasts and higher plants. The wild type of Ophiostoma multiannulatum cannot grow on galactose as the sole source of carbon, but two types of mutants which can grow on galactose have been isolated (LINDBERG 1963).

It seems probable that the ability of an organism to use fructose, mannose and galactose depends upon its ability to convert the sugar in question into phosphorylated derivatives of glucose able to enter the main respiratory pathways (CAPutro et al. 1950, CocHRANE 1958, p. 62). Enzyme studies suggest that at least some fungi also have enzymes which catalyse the oxidation of $\mathrm{D}$-glucose and D-galactose without phosphorylation (Cooper et al. 1959, Gancedo et al. 1967). $\mathrm{L}$-Arabinose is a common constituent of plant polysaccharides, and is utilized by several fungi for growth. Of 49 species studied by Lilly and Barnett (1956), only one (Sporobolomyces salmonicolor) failed to grow on this sugar. All the other species made from fair to good growth on it. D-Arabinose, which is not so common in nature as the Lisomer, was a markedly poorer carbon source than L-arabinose (LILLy \& BARNetT 1956). The mode of utilization of L-arabinose in fungi is not known, but it is likely that it enters the phosphogluconate oxidation pathway (Cochrane 1958, p. 64). It was somewhat surprising that both Cladosporium and Trichothecium used L-arabinose very weakly for growth.

The data of Gleason et al. (1970) as well the data of Gleason (1968) and Unestam (1965) suggest that capacities to utilize nutrients (including sugars and amino acids) might have some value as taxonomic characters in the Oomycetes. However, in the higher fungi there seems to be no clear correlation between the utilization of known carbohydrate sources and the systematic position of the fungus species (cf. Table 1).

From the above discussion it can be concluded that the sugars D-glucose, D-fructose and sucrose, which are the main constituents of the free sugar pools of higher plants, serve as excellent carbon sources for Cladosporium. Trichothecium could not use sucrose, but $\mathrm{D}$-glucose and $\mathrm{D}$-fructose were good carbon sources for it. On the other hand, the sugars that are unusual in the free state in higher plants, e.g. D-galactose and L-arabinose, were utilized very weakly by these fungi for growth. It seems obvious that the sugar content of the host plant can affect the growth of these fungi.

\section{Acknowledgements}

The present study was carried out at the Department of Botany, University of Helsinki, during the years 1968-1971.

We wish to thank Custos Emeritus Heikki Roivainen, Ph.D., for determining the fungi, and $\mathrm{Mr}$. Arvi Salonen, Lic.Agr., for giving us Trichothecium roseum strain. Our thanks are also due to Mrs. Jean Margaret Perttunen, B.Sc. (Hons.), for revision of the English text. 


\section{References}

Agnimotri, V. P. 19.62: Studies on Aspergilli. (V). Utilization of monosaccharides by some ascosporic members of the Aspergillus nidulans group. Flora 152:81—90.

Butler, B. J. \& Jones, S. G. 1949: Plant pathology. Macmillan \& Co. LTD., London, $730 \mathrm{pp}$.

Ciaputto, R., Leloir, L. F., Cardint, G. E. \& Paladini, A. C. 1950: Isolation of the coenzyme of the galactose phosphate - glucose phosphate transformation. J. Biol. Chem. $184: 333-350$.

Grrillo, V. P. 1961: Sugar transport in microorganisms. Ann. Rev. Microbiol. 15:197218.

Cochrane, V. W. 1958: Physiology of fungi. John Wiley \& Sons, New York and London, 542 pp.

Cooper, J. A. D., Smith, W., Bacila, M. \& MeDINA, H. 1959: Galactose oxidase from $\mathrm{Po}-$ lyporus circinatus, Fr. J. Biol. Chem. 234: 445-448.

Domsch, K. H. 1960: Das Pilzenspektrum einer Bodenprobe II Nachweis physiologischer Merkmale. Arch. Mikrobiol. 35:229-247.

Evans, D. L. 1928: Chemical studies in the physiology of apples. VII. A study of the sugars of apples with especial reference to the fructose/glucose ratio. Ann. Bot. (London) $42: 1-28$.

Fergus, G. L. 1952: The nutrition of Penicillium digitatum Sacc. Mycologia 44:183-189.

Fries, L. 1955: Studies in the physiology of Coprinus. I. Growth substance, nitrogen and carbon requirements. Svensk. Bot. Tidskr. $49: 476-529$.

Gancedo, J. M., Gancedo, G. \& Asensio, G. 1967: Widespread occurrence of galactose oxidase and glucose oxidase in fungi. Arch. Biochem. Biophys. 119:588-590.

Gautheret, R. J. 19.59: La culture des tissus végétaux. Masson et Cie, Paris, 863 pp.

Gleason, F. H. 1968: Nutritional comparisons in the Leptomitales. Am. J. Bot. 55:1003 1010.

Gleason, F.H., Stuart, T.D. Prige, J. S. \& Nelbach, E. T. 1970: Growth of certain aquatic Oomycetes on amino acids. II. Apodachlya, Aphanomyces, and Pythium. Phys. Plant. 23:769-774.
Hare, R. T. 1966: Physiology of resistance to fungal diseases in plants. Bot. Rev. 32:95137.

Lilly, V. G. \& Barnetr, H.L. 1951: Physiology of the fungi. McGraw-Hill, New York, Toronto and London, $464 \mathrm{pp}$.

Lilly, V. G. \& BarnetT, H.L. 1956: The utilization of D- and L-arabinose by fungi. Am. J. Bot. 43:709-714.

LindBerg, M. 1963: Galactose as a carbon source for the growth of Ophiostoma multiannulatum. Phys. Plant. 16:661-673.

Lopez, M. E. \& Fergus, C. L. 1965: The carbon and nitrogen nutrition of Fusarium roseum. Mycologia 57:897-903.

Moore, W. C. 1959: British parasitic fungi. University Press, Cambridge, $430 \mathrm{pp}$.

Palmer, J. G. \& Hacskaylo, E. 1970: Ectomycorrhizal fungi in pure culture I. Growth on single carbon sources. Phys. Plant. 23:1187 $-1197$.

Pohjakallio, O. 1932: Sokerien merkityksestä eräiden ruostesienien ravintoaineena. Acta Agr. Fenn. 25:1-93.

Srmola, L. K. 1969: Comparative studies of the sugar pools of three Lathyrus species. Acta Bot. Fenn. 85:1-16.

Sorenson, W. G. \& Hesseltine, C. W. 1966: Carbon and nitrogen utilization by Rhizopus oligosporus. Mycologia 58:681-689.

Steinberg, R. A. 1942: The process of amino acid formation from sugars in Aspergillus niger. J. Agr. Res. 64:615-635.

Turner, J. F., Turner, D. H. \& Lee, J. B. 1957 : Physiology of pea fruits. IV. Changes in sugars in the developing seed. Austr. J. Biol. Sci. 10:407-413.

Unestam, T. 1965: Studies on the crayfish plague fungus Aphanomyces astaci I. Some factors affecting growth in vitro. Phys. Plant. 18: $483-505$.

WARIS, H. 1962: Neomorphosis in seed plants induced by amino acids II. Oenanthe lachenalii. Phys. Plant. 15:736-752.

YLIMÄKI, A. 1970: The microflora of Finnish cereal seeds. Ann. Acad. Sci. Fenn. A. IV. 168:71-72.

Yu-Sun, C. C. C. 1964: Nutritional studies of Ascobolus immersus. Am. J. Bot. 51: $231-$ 237. 